\title{
Congenital Pulmonary Artery Stenosis
}

National Cancer Institute

\section{Source}

National Cancer Institute. Congenital Pulmonary Artery Stenosis. NCI Thesaurus. Code C99897.

A cong enital cardiovascular abnormality characterized by the narrowing of the lumen of the main pulmonary artery or its branches. It may be associated with other congenital heart malformations. Signs and symptoms include dyspnea, tachypnea, tachycardia, fatigue, and edema. 